\title{
Determination of acrylamide in dry feedstuff for dogs and cats
}

\author{
Helena Veselá, Emanuel Šucman \\ University of Veterinary and Pharmaceutical Sciences Brno, Faculty of Veterinary Hygiene and Ecology, \\ Institute of Biochemistry, Chemistry and Biophysics, Brno, Czech Republic
}

Received September 4, 2012
Accepted March 19, 2013

\begin{abstract}
Acrylamide is considered to be an endogenous contaminant of food and feedstuff. Attention is paid to the acrylamide content in human nutrition products; however, there is lack of data about its concentrations in feedstuff. The aim of this study was to use a newly developed adsorptive stripping voltammetry procedure for determination of acrylamide concentrations in five and three different kinds of dog and cat dry feedstuff, respectively. The applied analytical procedure consists of a solvent extraction in ultrasound bath, followed by voltammetric measurement at the hanging mercury drop electrode in ammonia buffer. The accuracy of the method was verified by use of standard reference materials. The range of acrylamide concentration found in samples of dry dog and cat feedstuff ranged from 106 to $358 \mu \mathrm{g} / \mathrm{kg}$, and from 66 to $269 \mu \mathrm{g} / \mathrm{kg}$, respectively. The precision of analyses expressed in form of the relative standard deviations ranged between $0.6-1.7 \%$. The voltammetric procedure appears to be a reliable, sensitive, rapid and low-cost analytical technique for the determination of acrylamide in food and feedstuff. The concentrations of acrylamide found in feedstuff were relatively moderate but it is undoubtedly necessary to monitor its concentrations in future.
\end{abstract}

Dry dog feed, dry cat feed, endogenous contaminant, analysis, voltammetry

Acrylamide (AA) is a commercially produced substance. It can be naturally formed at high temperatures in food/feedstuff rich in starch. The major pathway of AA formation is a reaction between an amino acid and a carbonyl group of reducing sugar, known as Maillard reaction. Acrylamide can be absorbed by animals and humans via ingestion, inhalation or through the skin. Regardless of the route of absorption, AA is distributed relatively rapidly to all tissues. It was found in human tissues such as in the thymus, liver, heart, brain, kidneys, placenta and breast milk that the major metabolite glycidamide is formed due to oxidation of AA by cytochrome P450. Acrylamide and glycidamide can bind in vivo haemoglobin, serum albumins, DNA, and enzymes. Acrylamide affects both humans and animals. Typical symptoms of acrylamide exposure include ataxia and skeletal muscle weakness (Capuano and Fogliano 2011). The International Agency for Research on Cancer (IARC 1997) has classified acrylamide in Group 2A (probable carcinogen to humans). Acrylamide is a multi-organ carcinogen that causes tumours of lungs, uterus, mammary gland etc. It was confirmed that AA causes cancer in mice and rats (Törnquist 2005). Genetic toxicity and reproductive toxicity have been proven in a variety of biological assays (Von Mühlendahl and Otto 2003; Törnquist 2005; Capuano and Fogliano 2011). A comprehensive detailed overview of acrylamide contents in different kinds of food and of methods available for its determination is given in the EFSA Report (2012).

Analytical methods suitable for the determination of acrylamide in food and/or feedstuff have been explored. Gas chromatography (GC), high performance liquid chromatography (HPLC) and capillary electrophoresis (CE) have been used for determination of acrylamide in food being predisposed to acrylamide formation. The technique of HPLC equipped with mass spectrometry (MS) detector is most often used (Keramat 2001; Zhang et al. 2005; Tekkeli et al. 2012). Electrochemical methods are widely used in environmental and/or

Address for correspondence:

Prof. RNDr. Emanuel Šucman, CSc.

Institute of Biochemistry, Chemistry and Biophysics

University of Veterinary and Pharmaceutical Sciences Brno_ Phone: +420541562603

Palackého tř. 1/3, 61242 Brno

E-mail: sucmane@vfu.cz

Czech Republic

http://actavet.vfu.cz/ 
nutritional assessments. The advantage of the electrochemical approach is a relatively short measuring time including sample preparation (Wang 2001). Amounts of acrylamide were measured by square-wave voltammetry in potato chips (Zargar et al. 2009). Recently, a new approach to electrochemical determination of AA was published (Ves elá and Šu cman 2013). In this study the use of adsorptive differential pulse voltammetry for determination and quantification of the AA content in food and feedstuff was described. The analytical properties of this newly developed electroanalytical method are described as well as its comparison with common chromatographic methods, especially the HPLC techniques. In the available literature data on the content of AA in feedstuffs are absent. Nevertheless, their composition and/or technological processes make possible the occurrence of AA in this material.

The aim of this study was to check the usefulness of the new electrochemical method to analyse the amounts of acrylamide in dry dog and cat feedstuffs.

\section{Material and Methods}

\section{Material for analysis}

The content of acrylamide was measured in five randomly selected dry dog feedstuffs purchased from local markets: Friskies junior dry, Purina (Nestlé Česko s.r.o.), Chappi dry dog foods - meat and vegetables (Mars Czech s.r.o.), Propesko complete menu for small and medium breeds (ProvimiPet Food CZ s.r.o.), Darling with meat and added selected vegetables, Purina (Nestlé Česko s.r.o.) and Butcher's dry complete - beef (Butcher's Pet Care Ltd, UK). Furthermore, three randomly selected dry cat foodstuffs were purchased: Friskies indoor cats, Purina (Nestlé Česko s.r.o.), Kitekat dry beef vegetables (Mars Czech s.r.o) and Perfect fit sensitive (Mars Czech s.r.o.). All the feedstuffs are registered for use in the Czech Republic and their composition complies with assessed ranges. Five grams of each feedstuff sample were taken for analysis. Rusk (European Reference Material ERM $^{\circledR}$-BD274, Germany) and crispbread (European Reference Material ERM ${ }^{\circledR}$-BD272, Germany) were used as the Standard Reference Materials (SRM) in order to check the accuracy of analysis. The other alternative was the use of recovery measurements because none SRM for feedstuff exist.

\section{Chemicals}

Mercury (polarographic grade) and acrylamide (electrophoresis grade) were supplied by Merck (Germany). Nickel solution Astasol (Analytika, Czech Republic) was used $(1.000 \pm 0.005 \mathrm{~g} / \mathrm{l})$. In order to remove dissolved oxygen from solutions Argon (Linde Technoplyn a.s., Czech Republic) was used. All chemicals used for samples and/or standard preparation were of analytical grade (Merck, Germany). Ultra-pure water (GenPure, TKA GmbH, Germany) of specific conductivity $<1 \mu \mathrm{S} \cdot \mathrm{m}^{-1}$ was used to prepare all solutions.

\section{Equipment}

Measurement of acrylamide concentration was performed by the Autolab measuring unit (Eco Chemie B.V., Netherlands) equipped with the electrode system VA Stand 663 (Metrohm, Switzerland). The software Nova 1.5 (Eco Chemie B.V., Netherlands) was used for measurement control and evaluation. The hanging mercury drop electrode was the working electrode; the $\mathrm{Ag} / \mathrm{AgCl}$ was the reference electrode $(3 \mathrm{~mol} / \mathrm{l} \mathrm{KCl})$, and the glassy carbon electrode was used as the auxiliary electrode.

\section{Procedure}

The principle of the method is known as the adsorptive stripping voltammetry which is based upon formation of a complex compound of AA with $\mathrm{Ni}^{2+}$. Such complex can be adsorbed on the surface of the mercury working electrode and measured after sufficient accumulation time. The parameters of the measurement procedure had been thoroughly evaluated in order to find the set of optimal conditions. The exact analytical procedure was described in article by Veselá and Šucman (2013).

The statistical methods used for data evaluation are described in Eckschlager et al. (1980).

\section{Results}

In both SRMs and samples the peak heights were found to be a function of acrylamide concentration and/or deposition time. Measurement parameters were thoroughly set in order to get appropriate results. A linear relationship between currents of peak maxima and concentration of AA was found. The detection limit of the method was $12 \mu \mathrm{g} / \mathrm{kg}$ under the selected measurement conditions. 


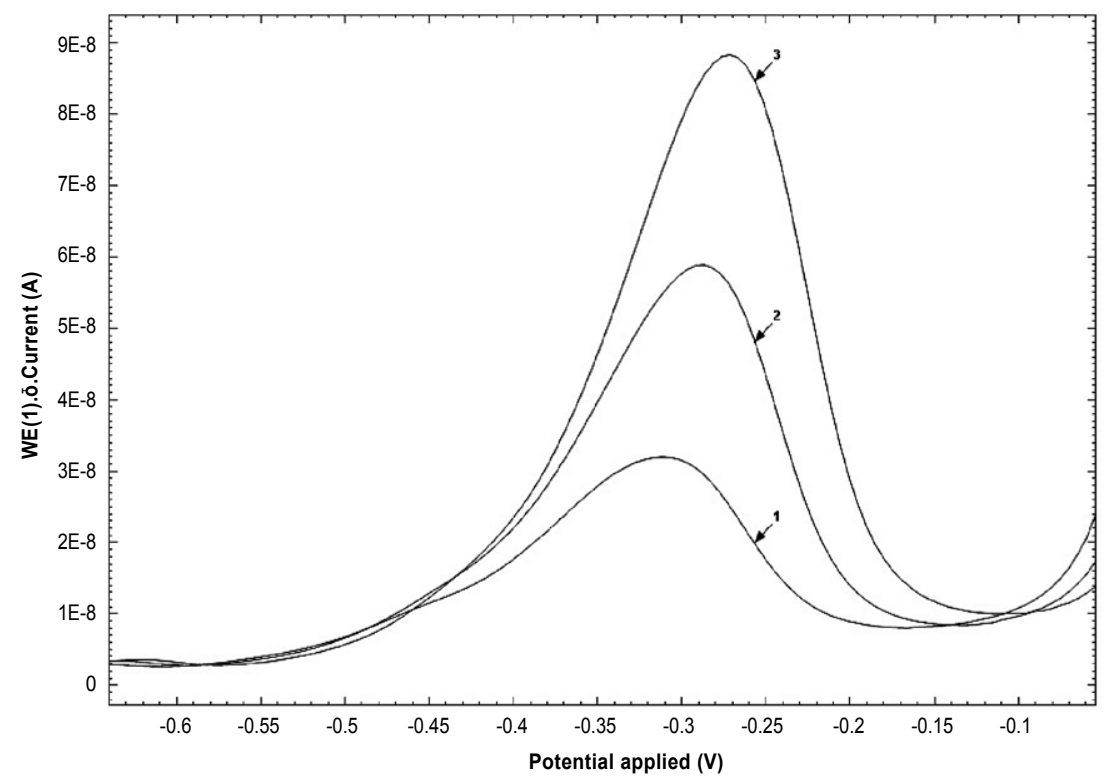

Fig. 1. Voltammetric curves of acrylamide in the standard reference material rusk

$\mathrm{E}_{\mathrm{d}}=-0.72 \mathrm{~V}, \mathrm{E}_{\mathrm{e}}=-0.05 \mathrm{~V}, \mathrm{SR}=5 \mathrm{mV} / \mathrm{s}, \mathrm{PH}=50 \mathrm{mV}, \mathrm{T}_{\mathrm{d}}=300 \mathrm{~s}$. Curves: $1-$ sample $(200 \mu \mathrm{l}), 2-$ standard addition (1.56 ng of acrylamide), 3 - standard addition ( $3.13 \mathrm{ng}$ of acrylamide)

$\mathrm{E}_{\mathrm{d}}$-deposition potential (V), $\mathrm{E}_{\mathrm{e}}-$ final potential $(\mathrm{V}), \mathrm{SR}$-scan rate $(\mathrm{V} / \mathrm{s}), \mathrm{PH}-$ peak height $(\mathrm{mV}), \mathrm{T}_{\mathrm{d}}$-deposition time (s).



Fig. 2. Dependence of peak heights on the concentration of acrylamide in the standard reference material rusk $\mathrm{m}$ - amount of added acrylamide (ng), I - measured current (A)

Samples of standard reference materials (Rusk BD-272 and Crispbread BD-274) were analysed in order to confirm the accuracy of the applied method. Additionally, the accuracy was also checked in real samples using the standard addition approach. An example of voltammogram and its evaluation is given in the Figs 1 and 2. The linear relationship between peak currents and concentrations is clearly seen. The measured values were 
Table 1. Concentrations of acrylamide in standard reference materials.

\begin{tabular}{lccccc}
\hline Sample & $\mathrm{n}$ & Certified $(\mu \mathrm{g} / \mathrm{kg})$ & $95 \% \mathrm{CI}(\mu \mathrm{g} / \mathrm{kg})$ & $\mathrm{s}(\mu \mathrm{g} / \mathrm{kg})$ & $\mathrm{RSD}(\%)$ \\
\hline Rusk BD-272 & 3 & $72 \pm 4$ & $77 \pm 10$ & 4.7 & 6.1 \\
Crispbread BD-274 & 4 & $980 \pm 90$ & $992 \pm 113$ & 92.8 & 9.3 \\
\hline
\end{tabular}

$\mathrm{n}$ - number of samples, CI - 95\% confidence interval, s - standard deviation, RSD - relative standard deviation

Table 2. Concentrations of acrylamide in dry dog feedstuff.

\begin{tabular}{llccc}
\hline Sample & $\mathrm{n}$ & $95 \% \mathrm{CI}(\mu \mathrm{g} / \mathrm{kg})$ & $\mathrm{s}(\mu \mathrm{g} / \mathrm{kg})$ & $\mathrm{RSD}(\%)$ \\
\hline Friskies & 3 & $214 \pm 3$ & 1.2 & 0.6 \\
Chappi & 3 & $106 \pm 3$ & 1.2 & 1.1 \\
Propesko & 3 & $117 \pm 4$ & 1.8 & 1.5 \\
Darling & 3 & $358 \pm 13$ & 5.9 & 1.7 \\
Butcher's & 3 & $222 \pm 7$ & 3 & 1.3 \\
\hline
\end{tabular}

$\mathrm{n}$ - number of samples, 95\%CI - confidence interval, s - standard deviation, RSD - relative standard deviation

Table 3. Accuracy checking in samples of dry dog feedstuff using acrylamide standard addition.

\begin{tabular}{llccc}
\hline Sample & $\mathrm{n}$ & $95 \% \mathrm{CI}(\mu \mathrm{g} / \mathrm{kg})$ & Added AA $(\mu \mathrm{g} / \mathrm{kg})$ & Recovery $(\%)$ \\
\hline Friskies & 3 & $427 \pm 5$ & 214 & 99.8 \\
Chappi & 3 & $210 \pm 4$ & 106 & 99.1 \\
Propesko & 3 & $231 \pm 5$ & 117 & 98.7 \\
Darling & 3 & $715 \pm 12$ & 358 & 99.9 \\
Butcher's & 3 & $439 \pm 6$ & 222 & 98.9 \\
\hline
\end{tabular}

$\mathrm{n}$ - number of samples, $95 \% \mathrm{CI}$ - confidence interval, AA - acrylamide

Table 4. Concentrations of acrylamide in dry cat feedstuff.

\begin{tabular}{lcccc}
\hline Sample & $\mathrm{n}$ & $95 \% \mathrm{CI}(\mu \mathrm{g} / \mathrm{kg})$ & $\mathrm{s}(\mu \mathrm{g} / \mathrm{kg})$ & $\mathrm{RSD}(\%)$ \\
\hline Friskies & 3 & $269 \pm 7$ & 3 & 1.1 \\
Kitekat & 3 & $103 \pm 4$ & 1.8 & 1.7 \\
Perfect Fit & 3 & $66 \pm 1$ & 0.6 & 0.9 \\
\hline
\end{tabular}

$\mathrm{n}$ - number of samples, 95\%CI - confidence interval, s - standard deviation, RSD - relative standard deviation

$77 \pm 10 \mu \mathrm{g} / \mathrm{kg}$ and $992 \pm 113 \mu \mathrm{g} / \mathrm{kg}$ for rusk and crispbread, respectively. Concentrations of acrylamide found in these SRMs are in good agreement with the data specified in their certificates (Table 1).

The results of AA determination in dog dry feedstuff are given in Table 2. Acrylamide was found at a concentration ranging from 106 to $358 \mu \mathrm{g} / \mathrm{kg}$. The relative standard deviation ranged from 0.6 to $1.7 \%$. The calculated recoveries with known standard additions of AA (Table 3) for this feedstuff are close to the required 100\% (98.7-99.8\%); no significant deviation was found.

The results found in dry cat foodstuff are given in the Table 4. Acrylamide was found 
Table 5. Accuracy checking in samples of dry cat feedstuff using acrylamide standard addition.

\begin{tabular}{lcccc}
\hline Sample & $\mathrm{n}$ & $95 \% \mathrm{CI}(\mu \mathrm{g} / \mathrm{kg})$ & Added AA $(\mu \mathrm{g} / \mathrm{kg})$ & Recovery $(\%)$ \\
\hline Friskies & 3 & $533 \pm 4$ & 269 & 99.1 \\
Kitekat & 3 & $204 \pm 5$ & 103 & 99 \\
Perfect Fit & 3 & $132 \pm 7$ & 66 & 100 \\
\hline
\end{tabular}

$\mathrm{n}$ - number of samples, $95 \% \mathrm{CI}$ - confidence interval, AA - acrylamide

at a concentration ranging from 66 to $269 \mu \mathrm{g} / \mathrm{kg}$. Relative standard deviation of results ranged from 0.9 to $1.1 \%$. The calculated recoveries of added AA standard (Table 5) in this feedstuff were close to the required 100\% (99-100\%); no significant deviation was found. This gives the evidence for the adequate accuracy of the applied voltammetric method for determination of AA in feedstuff.

\section{Discussion}

There is a lack of data about acrylamide concentrations in dog and cat dry feedstuff in the available literature. This study introduces a new way for acrylamide determination in feedstuff. The voltammetric procedure seems to be a reliable, sensitive, rapid and low-cost analytical technique for determination of acrylamide in the above mentioned feedstuff. The total analysis time including the extraction step and measurement evaluation was approximately $2 \mathrm{~h}$. The measured and calculated recoveries of acrylamide both in dog and in cat dry food as well as the results measured in reference materials proved the adequate accuracy of the method. The precision expressed in terms of relative standard deviations ranged from 0.6 to $1.7 \%$ which is satisfactory for this kind of analysis.

The total analysis time including the extraction step and measurement evaluation was approximately $2 \mathrm{~h}$. The concentrations found were relatively moderate compared to human food. Nevertheless, there is no doubt that acrylamide, relatively new carcinogenic endogenous contaminant, is present also in these feedstuffs. Therefore it is necessary to monitor its concentrations.

\section{Acknowledgements}

This research was supported by the Ministry of Education, Youth and Physical Training of the Czech Republic (Research Plan Veterinary Aspects of Food Quality and Safety, MSM 6215712402).

\section{References}

Capuano E, Fogiliano V 2011: Acrylamide and 5-hydroxymethylfurfural (HMF): A review on metabolism, toxicity, occurrence in food and mitigation strategies. LWT - Food Sci Technol 44: 793-810

Eckschlager K, Horsák I, Kodejš Z 1980: Evaluation of analytical methods. (In Czech) SNTL, Alfa Praha, Bratislava $223 \mathrm{p}$.

International Agency for Research on Cancer (IARC) - Summaries and Evaluations. Acrylamide (Group 2A). Available at: http://www.inchem.org/documents/iarc/vol60/m60-11.html. Last modified August 26, 1997. Accessed August 16, 2012.

Keramat J, Lebail A, Prost C, Soltanizadeh N 2011: Acrylamide in foods: Chem Anal A review. Food Bioprocess Tech 4: 340-363

Scientific report of EFSA 2012: Update on acrylamide levels in food from monitoring years 2007 to 2010. EFSA Journal 10: 38 p. Available at: http://www.efsa.europa.eu/efsajournal. Last modified October 23, 2012. Accessed January 3, 2013.

Tekkeli SEK, Onal C, Onal A 2012: A review of current methods for the determination of acrylamide in food products. Food Anal Methods 5: 29-39

Törnqvist M 2005: Acrylamide in food: The discovery and its implications. Adv Exp Med Biol 561: 1-19

Veselá H, Sucman E 2013: Determination of acrylamide in food using adsorption stripping voltammetry. Czech J Food Sci (in press) 
Von Mühlendahl KE, Otto M 2003: Acrylamide: more than just another food toxicant? Eur J Pediatr 162: 447-448 Wang J 2001: Analytical electrochemistry. John Wiley and Sons, Inc., New York, 222 p.

Zargar B, Sahraie NR., Khoshnam F 2009: Catalytic square-wave voltammetric determination of acrylamide in potato chips. Anal Lett 42: 1407-1417

Zhang Y, Zhang GY, Zhang Y 2005: Occurrence and analytical methods of acrylamide in heat-treated foods, review and recent developments. J Chromatogr A 1075: 1-21 